\title{
Laura Watts (2018) Energy at the End of the World. An Orkney Islands Saga. Cambridge and London: The MIT Press. 440 pages. ISBN 978-0262038898
}

\author{
Veera Kinnunen \\ veera.kinnunen@ulapland.fi
}

Jarno Valkonen

The energy in these islands is a literal force that changes the body, and so changes what you know about the world. (Watts, p. 50)

The saga of the Energy Islands by science and technology studies scholar Laura Watts begins with a cup of tea. The reader is offered a cup of steaming hot black tea with milk, and s/he is invited to join the author for a walk and meet the Orkney Islands in all their messy, multisensory presence. The author then reminds the reader to pull on wellingtons and woollen mittens in order to bear with the force of the harsh island winds.

The focus of the book is on the making of energy futures. Watts takes a lead from science scholar Lucy Suchman who points out that innovations are not universal: they change when they travel from place to place. This view emphasizes that place matters - place itself is an effect. Landscape has agency in future-making. The energy future of the Orkney is irreducible from the place itself, its geography, history and culture. In any other place, the future of the low-carbon renewable energy would have to be made differently. Thus, Watts turns attention to the situated practices of energy future-making. From this place-specific point of view, she weaves a story of what happens to the future when it is being locally imagined and crafted. By scrutinizing closely the present "struggling, overheating, and partial electrical flows" in the cables of Orkney Islands, Watts asks: how could energy futures be made otherwise? (p. 68).

The study is based on ten years of ethnographic fieldwork in Orkney, an archipelago of around 20 populated islands that lie ten miles off the northeast coast of mainland Britain. Over the last decades, Orkney and its open-sea marine energy test site have become the centre of the ongoing revolution in sustainable power generation. The European Marine Energy Centre, EMEC (pronounced "ee-mek" as Watts notes) located in Orkney, has tested 30 different devices since its launch in 2003. Many other marine energy test sites around the world draw from the expertise of Orkney. In this respect, the Orkney Islands undoubtedly exert a significant impact on the future of renewable energy in the whole world: A local adaptation of low-carbon renewable energy future that the contemporary world so badly needs is already being lived in the Orkney Islands. In addition, as Watts points out, the Orkney Islands have another, less visible, but no less important, impact on the energy-futures of the world. The Islands are a living example of skilful resourcefulness of common people in energy generation. While peripheries are often represented as passive producers of resources, this study emphasizes the dynamic vibrancy of the edges. Whereas cities are utterly dependent on their edges, the resourceful edges have learned to make do without the 
centres. Getting by independently in the remote islands even when the connection to the mainland is cut off, as it often is, necessitates becoming both interdependent and inventive. In order to cope, one needs to form alliances with every body including non-human agents, such as rocks, winds and tides. Thus, the islanders constantly seek ways to ally with the plentiful natural forces-They have come up with community-owned wind turbines, self-customized electric cars turned into powerstoring mobile batteries, and ferries fuelled with wave-power. This forced and learned "make do" attitude makes the islands a flexible and openminded place where different infrastructural solutions to the emerging problems are being constantly anticipated, imagined and trialled. Watts's description of being innovative at the end of the world reminds us of Tim Ingold's definition of design as a continuous process of dwelling, of making life liveable. The islander resilience is about making do with what one's got and being resourceful in inventing ways of getting by.

The saga of electricity is a saga of infrastructures. It pays attention to the power of infrastructures to hold over time and to define certain futures. Moreover, it draws attention to the work that is needed to maintain the stability and invisibility of the infrastructures. By focusing on the resourceful coping and experimenting with energy infrastructures - and occasional failure in these attempts - Watts emphasizes that as static as they may seem, they are not eternally unchanging.

Focusing on the frictions of making energy - the situated entanglements of Orkney 'electropolitics' - illustrates how complicated issue energy is. It is an untidy bundle of technology and natural forces, science and markets, history and future, national and local politics, calculations and sensory perceptions, dreams, hopes and fears, infrastructures and improvising, and it is as much a question of high-tech innovation and resourceful tinkering. By following the sometimes painfully difficult processes of turning the overflowing 'natural' elements, such as wind and waves, into utilizable form, the reader realises that 'energy' is not a generalizable issue but rather constituted in and through specific places and times. In the Energy Islands, the question of energy is a constantly pressing issue, an inseparable part of everyday life.

Energy at the end of the world is also a writing experiment. Methodologically, Watts follows in the footsteps of Donna Haraway and other feminist science studies scholars, who have called for recognizing the coupling together of writing as creative craft and academic research. In her saga, Watts pushes the boundaries of fact and fiction ("Stories and Fables") and weaves them together into an empirical experiment on feminist science studies. Donna Haraway defines SF (meaning simultaneously Science Fiction, Speculative Fiction, Speculative Fabulation, or Feminist Fabulation) as worlding - writing as a knowledgemaking and world-making practice. Thus, SF is less about critically observing and analysing the existing world, and more about being mindful of the worlds that the writing opens, and also about bearing its consequences. As Watts puts it: "Tales have the power to make the future - or rather, some futures for some people" (p. 11).

Albeit being speculative and fabulated, the Energy Islands saga is far from fictive. It is based on a long-term, meticulous and committed ethnographic fieldwork on the islands. The ethnographic material alone comprises over 10,000 words of field notes and 2,000 photographs. As a serious anthropologist, Watts takes the myths, gossip and other marginal forms of knowing as seriously as historical narratives, numeric information and other scientific 'facts'. Although Watts's text structurally follows the conventions of academic writing and uses a reference-based format, she plays with experimental forms of ethnography by drawing from eclectic sources, using first-person narrative, and seeking to address the creative process of research itself, rather than reporting generalized findings. The traditional research text is enriched and complemented with, for instance, an orally chanted poem, photographs, vividly narrated accounts of encounters with a female monster Electric Nemesis, and even series of comic-style illustrations of this fictional monster.

Watts composes her saga of Orkneyan electropolitics from fragments of actual and imagined events, encounters and stories and through these accounts, she shows the richness of elements entangled in the making of energy futures. 
With Watts's authorial prowess, the outcome is an extremely enjoyable read. She is not just a scientist, but also a great storyteller. Energy at the end of the world succeeds in being a piece of research that is so captivating that the reader is unable to put the book down - a rare reading experience in the academic genre

Laura Watts's study is about making energy futures. However, the study itself is a contribution to future-making in that it paves the way for the future ethnographers of science and technology studies. It shows what ethnographic science and technology studies can do at their best, and how scientific texts can be enjoyable, inspiring and convincing. For those in doubt, the book is a powerful proof that the social sciences and humanities can offer valuable insights into research on technologies and energy infrastructures e.g. by bringing forth the complexity of more-than-human entanglements needed to produce energy, and by revealing the uneven power relations and multiple ontologies at play in the situated practices of making futures, and showing the efforts that it takes to work and fit these different realities together. 